\title{
Utilização da Metodologia Ágil no Desenvolvimento de Software na Justiça Eleitoral Brasileira
}

\author{
Vinícius S. Santos ${ }^{1}$, Edna D. Canedo ${ }^{2}$ \\ ${ }^{1}$ Seção de Voto Informatizado - Tribunal Superior Eleitoral (TSE) \\ Brasília - DF - Brasil \\ 2Faculdade UnB Gama - Universidade de Brasília (UnB) \\ Caixa Postal 8114 - 72.405-610 - Gama - DF - Brasil \\ vinicius.santos@tse.jus.br, ednacanedo@unb, br
}

\begin{abstract}
This paper presents a case study about an application of agile methodology using the framework Scrum combined with the agile software development process XP (Extreme Programming) in projects about building systems in the Brazilian Electoral Superior Court - TSE. In order to discover new knowledge relevant to the business, it was analyzed evidence collected on the implementation of the methodology and confronted with the most used bibliography about the subject. At the end of the investigation, necessary improvements were found out, and part of them confirmed facts previously known by the managers, and some brought new knowledge which presents a great potential of improvements in the organization.
\end{abstract}

Resumo. Este trabalho apresenta um estudo de caso de uma aplicação da metodologia ágil usando o framework Scrum combinado com o processo de desenvolvimento de software XP (Extreme Programming) sobre projetos de construção de sistemas no Tribunal Superior Eleitoral. Com o intuito de descobrir novos conhecimentos de interesse para o negócio foram analisadas evidências coletadas sobre a implantação da metodologia no órgão público e confrontadas com a bibliografia mais utilizada sobre o assunto. Por fim, necessidades de melhorias foram encontradas, sendo que parte delas confirmaram fatos anteriormente conhecidos pelos gestores, e parte trouxe novos conhecimentos com grande possibilidade de aplicação na organização.

\section{Introdução}

Um processo não é uma prescrição rígida de como desenvolver um software. Ao contrário, é uma abordagem adaptável que possibilita às pessoas realizar o trabalho de selecionar e escolher o conjunto apropriado de ações e tarefas. A intenção é a de sempre, entregar software dentro do prazo e com a qualidade suficiente para satisfazer àqueles que patrocinaram sua criação e àqueles que irão utilizá-lo [Pressman 2011].

No TSE a gestão de projetos utilizada e classificada como ágil, é chamada de Scrum [Kniberg 2007]. Os princípios do Scrum são utilizados para orientar as tarefas de desenvolvimento focando em requisitos, análise, projeto, evolução e entrega. A técnica é aplicada na prática da construção dos softwares da justiça eleitoral brasileira pelo TSE, especificamente analisando a forma de trabalho no que tange à gestão de projetos 
conduzida pela equipe da SEVIN, que é a responsável por desenvolver os sistemas internos da urna eletrônica brasileira.

O objetivo deste trabalho é analisar os aspectos positivos e mapear as lacunas de uma implantação do framework Scrum para gerenciamento e organização dos projetos de desenvolvimento de softwares no TSE, uma vez que, este conhecimento poderá ser compartilhado com as demais seções do órgão e com os Tribunais Regionais Eleitorais de todo o Brasil que já demonstraram ter interesse no processo de trabalho da SEVIN. Dessa forma, foi elaborada uma proposta técnica com sugestões de melhoria conforme os resultados obtidos visando atender o ciclo de melhoria contínua do processo e excelência na prestação do serviço público.

Para um melhor entendimento deste trabalho, a sua organização é descrita a seguir. Na seção 2 são apresentados os conceitos de gestão de projetos ágeis e a evolução do sistema eleitoral brasileiro na visão do TSE. Na seção 3 é apresentada a aplicação prática por meio do estudo de caso aplicado. Na seção 4 são apresentados os resultados do estudo de caso, apontando os benefícios da adoção das práticas ágeis e as dificuldades encontradas. Por fim, na seção 5 a conclusão do trabalho.

\section{Gestão de Projetos Ágeis}

\subsection{Gestão de projeto de software}

A engenharia de software é provida em camadas, sendo que, o processo de software é uma camada composta de diversos subprocessos, dentre eles o processo de gerência de projetos. A figura 1 apresenta as camadas da engenharia de software:

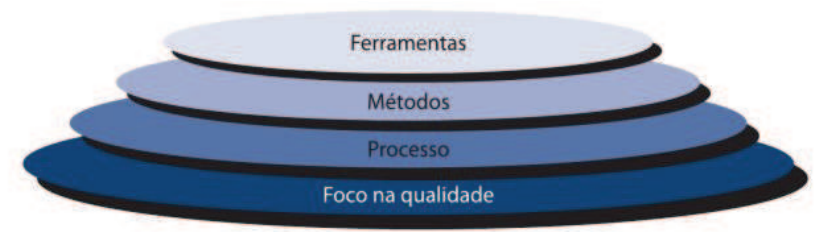

Figura 1. Camadas da engenharia de software [PRESSMAN 2011].

A gerência de projetos de software envolve, dentre outros tópicos, o planejamento e o acompanhamento das pessoas envolvidas no projeto, do produto sendo desenvolvido e do processo seguido para evoluir o software de um conceito preliminar para uma implementação concreta e operacional.

\subsection{Escolha do Scrum pelo TSE}

A escolha do Scrum foi baseada pelos seus princípios básicos de objetividade, papéis bem definidos e facilidade de aprendizado. Oferecendo um conjunto de práticas que tem como objetivo manter o gerenciamento do projeto visível aos usuários do modelo [Kniberg 2007]. O framework não detalha o que deve ser feito e não resolve os problemas da empresa, o objetivo do framework é prover visibilidade a estes problemas e servir como guia na resolução deles [Schwaber 2004, Varaschim 2009, Cohn 2003]. A figura 2 apresenta o fluxo do processo de desenvolvimento utilizando o Scrum: 


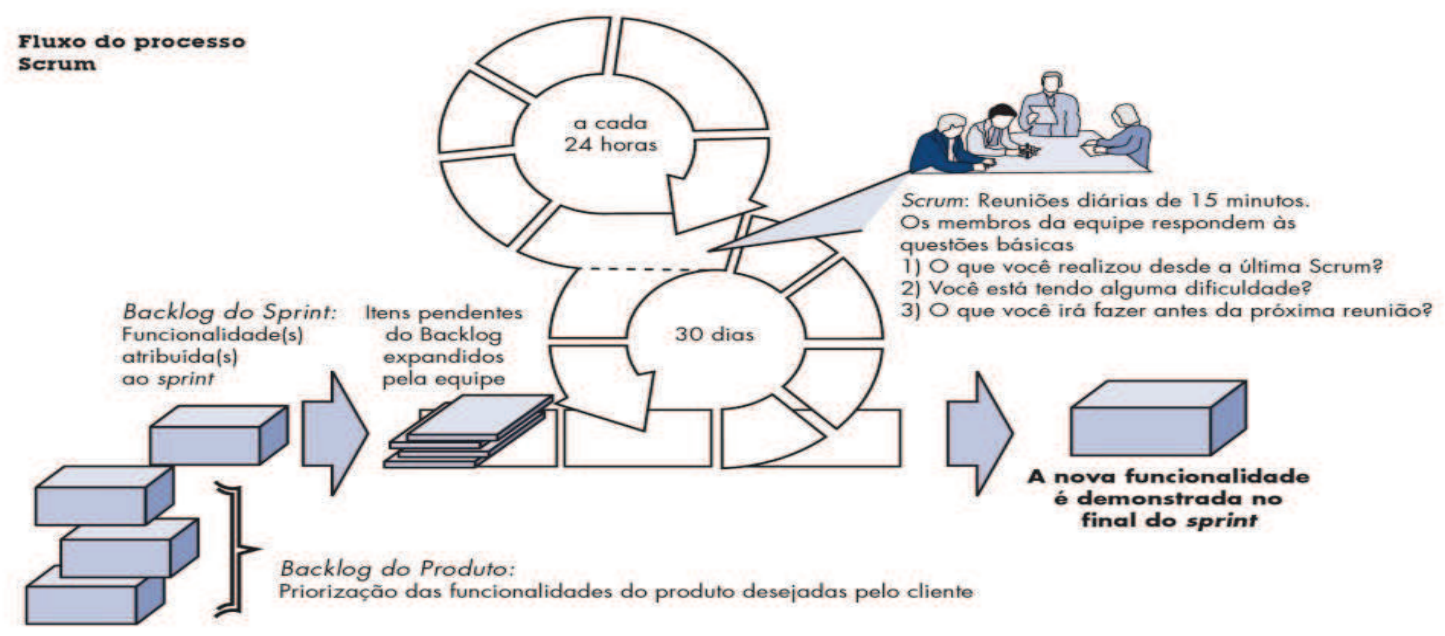

Figura 2. Fluxo do processo Scrum [Pressman 2011].

\subsection{Processo de desenvolvimento de software}

Um processo de desenvolvimento de software é definido como um roteiro que ajuda a criar um resultado de alta qualidade e dentro do prazo estabelecido, sendo sua utilização importante, porque propicia estabilidade, controle e organização para uma atividade que pode, sem controle, tornar-se bastante caótica. Entretanto, uma abordagem de engenharia de software moderna deve ser "ágil". Deve demandar apenas atividades, controles e produtos de trabalho que sejam apropriados para a equipe do projeto e para o produto a ser produzido [Pressman 2011].

No TSE existe um processo de desenvolvimento de software coorporativo chamado PRODUS, resumidamente, é o Processo Unificado - PU, largamente conhecido no meio acadêmico, com adaptações para atender as necessidades do tribunal. Entretanto, a SEVIN, de maneira pioneira dentro do órgão, e buscando aperfeiçoar o tempo de entrega de seus softwares, escolheu implantar o processo ágil XP (Extreme Programming), pois o projeto piloto escolhido era crítico - UENUX, sistema operacional da urna eletrônica - sendo preciso apresentar ao Product Owner as funcionalidades mais importantes, core business, em um curto prazo para que as mudanças nos requisitos não comprometessem a realização das eleições 2008.

\subsection{Combinando Scrum e XP no TSE}

Seguindo as orientações das melhores práticas do mercado de desenvolvimento de software foram combinados o Scrum e XP no TSE para que fossem alcançados resultados mais vantajosos para o órgão público, os detalhes da customização destas meteodologias usadas no TSE serão apresentados na seção de Resultados do Estudo de Caso.

Sobre este arranjo de metodologias [Kniberg 2007], o Scrum é focado nas práticas de gerenciamento e organização, enquanto o XP dá mais atenção às tarefas de programação. E ainda que, "Ambas as metodologias são baseadas em equipes localizadas juntas e membros de equipe fortemente colaborativos que programam em pares e encontram-se cara-a-cara todos os dias". 
De acordo com [Pressman 2011], “A Extreme Programming (programação extrema) emprega uma abordagem orientada a objetos como paradigma de desenvolvimento preferido e envolve um conjunto de regras e práticas constantes no contexto de quatro atividades metodológicas: planejamento, projeto, codificação e testes". A figura abaixo ilustra o processo XP e destaca alguns conceitos e tarefas-chave associados a cada uma das atividades metodológicas.

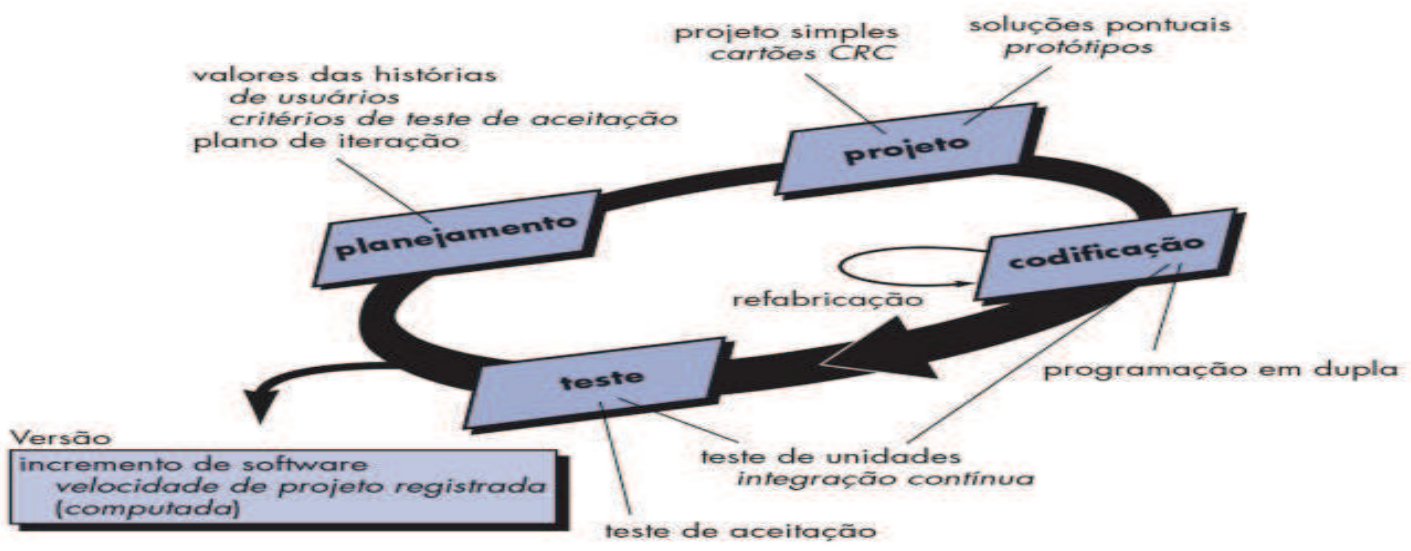

Figura 3. Fluxo do processo XP [Pressman 2011].

\section{Aplicação Prática}

As proposições propostas para este estudo de caso são: Primeira proposição - o processo de trabalho do Scrum é cognitivo, podendo ser entendido como um processo de produção de conhecimento. Segunda proposição - a implantação das metodologias ágeis se adequou ao processo de planejamento do TSE, adquirindo a racionalidade da cultura organizacional na qual está inserido. Terceira proposição - a promoção do desenvolvimento de software ágil de forma sustentável está baseada na capacitação das pessoas para a melhoria contínua da qualidade do produto entregue.

\subsection{Unidades de análise}

Para este estudo de caso a unidade de análise foi a Seção de Voto Informatizado SEVIN que está inserida na Coordenadoria de Sistemas Eleitorais - CSELE do órgão público federal Tribunal Superior Eleitoral - TSE, órgão máximo da Justiça Eleitoral, que exerce papel fundamental na construção e no exercício da democracia brasileira. Suas principais competências estão fixadas pela Constituição Federal e pelo Código Eleitoral.

A missão do TSE é garantir a legitimidade do processo eleitoral e o livre exercício do direito de votar e ser votado, a fim de fortalecer a democracia. A visão é consolidar a credibilidade da Justiça Eleitoral, especialmente quanto à efetividade, à transparência e à segurança. E os valores são a coerência: alinhamento entre discurso e prática; comprometimento: atuação com dedicação, empenho e envolvimento em suas atividades; respeito: reconhecimento e aceitação das diferenças entre as pessoas; inovação: estímulo à criatividade e à busca de soluções diferenciadas; flexibilidade: atitude de abertura permanente para compreender a necessidade de mudanças adotando medidas para promovê-las; integração: compartilhamento de experiências, 
conhecimentos e ações que conduzam à formação de equipes orientadas para resultados comuns; reconhecimento: adoção de práticas de estímulo e valorização das contribuições individuais e de grupos que conduzam ao cumprimento da missão do TSE; transparência: garantia do acesso às informações, ações e decisões institucionais; e ética: atuação sob os princípios da honestidade, lealdade e dignidade [TSE 2013].

\subsection{A evolução do voto no Brasil}

Ao longo da história da Justiça Eleitoral, expandiu-se e restringiu-se o universo dos que tinham o direito de votar, de acordo com a diretriz política de cada época. Com o tempo e a evolução da legislação, corrigiu-se a injustiça que afastava das urnas de votação mulheres, negros, analfabetos, religiosos e indígenas. Hoje, pode - se votar todo brasileiro maior de 16 (dezesseis) anos - independentemente de sexo, religião, etnia ou condição social. Significa que todos têm papel ativo na democracia e desfrutam do direito constitucional de escolher seus dirigentes e representantes.

Em 1983, o TSE começou a implantar um moderno sistema de informatização da Justiça Eleitoral, com a instalação de computadores nos TRE e nas zonas eleitorais. Doze anos depois, iniciava-se a votação eletrônica, que tornou o Brasil um modelo mundial. As eleições rápidas, eficientes e seguras puseram o país na vanguarda eleitoral do planeta [TSE 2013].

\subsection{Histórico do voto informatizado}

A informatização teve início em 1986 com o recadastramento eletrônico de aproximadamente 70 milhões de eleitores. Em 1994, fez-se, pela primeira vez, a totalização das eleições gerais pelo computador central, no TSE. Em 1995 iniciaram-se os trabalhos de informatização do voto. Uma comissão de juristas e técnicos de informática apresentou um protótipo da urna eletrônica. Em 1996 foi iniciada a primeira votação eletrônica do Brasil. Nas eleições de 1996, um terço do eleitorado votou nas urnas eletrônicas. Nas eleições de 1998, votaram, eletronicamente, dois terços dos eleitores. Finalmente, no ano 2000, o projeto foi implementado em sua totalidade, ocasião em que todo eleitorado votou por meio eletrônico. Todo o processo de informatização dos pleitos eleitorais tem sido permeado por estudos aprofundados e ações rígidas visando à segurança e à transparência do processo, possibilitando um fidedigno registro da vontade do eleitor brasileiro.

O voto informatizado surgiu para agregar mais qualidade, agilidade, transparência, segurança e robustez ao processo eleitoral. Tem sido uma ferramenta efetiva para o combate às fraudes. É um produto genuinamente brasileiro, único no mundo, concebido e construído sob a orientação do TSE, tanto o hardware das urnas eletrônicas como os milhares de programas computacionais que integram o sistema eletrônico de votação. A partir de 2005, todos os programas computacionais da votação eletrônica passaram a ser desenvolvidos pelo TSE [TSE 2013].

\subsection{Urna eletrônica brasileira}

A urna eletrônica é um microcomputador de uso específico para eleições, com as seguintes características: resistente, de pequenas dimensões, leve, com autonomia de energia e com recursos de segurança. Dois terminais compõem a urna eletrônica: o 
terminal do mesário, onde o eleitor é identificado e autorizado a votar (em alguns modelos de urna, onde é verificada a sua identidade por meio da biometria), e o terminal do eleitor, onde é registrado numericamente o voto.

A urna eletrônica somente grava a indicação de que o eleitor já votou. Pelo embaralhamento interno e outros mecanismos de segurança, não há nenhuma possibilidade de se verificar em quais candidatos um eleitor votou, em respeito à Constituição Federal brasileira, que determina o sigilo do voto.

Ao encerrar a votação, são gravados na mídia de resultado da urna eletrônica os seguintes arquivos: Boletim de urna; Registro digital do voto; Eleitores faltosos; Justificativas eleitorais; Registro de eventos (Log). Todos os arquivos são assinados digitalmente. O boletim de urna e o registro digital do voto, além de assinados, são criptografados.

\subsection{Os softwares eleitorais}

Com o intuito de quebrar paradigmas e inovar a SEVIN evoluiu sua forma de trabalho e implantou a metodologia ágil na seção para desenvolver os softwares eleitorais de sua competência. A motivação pode ser definida de maneira mais clara conforme [Múcio 2013].

"O aumento da popularidade do uso de metodologias ágeis de desenvolvimento de software no mercado nacional e internacional”. Essa realidade, somada às insatisfações frequentes das contratações de serviços geradas pelo uso do modelo corrente, tem levado algumas instituições públicas a acreditarem que podem obter melhores resultados com o uso das metodologias ágeis. "Nesse cenário, instituições públicas iniciaram investimentos nessa área, capacitando seus servidores e instituindo internamente em suas equipes de tecnologia da informação, quando possível, métodos ágeis para o desenvolvimento de suas soluções [Múcio 2013]”.

A metodologia ágil está sendo empregada nos seguintes produtos do ecossistema da urna eletrônica:

Tabela 1. Softwares desenvolvidos com metodologia ágil [TSE 2013].

\begin{tabular}{|c|c|}
\hline Nome & Descrição \\
\hline $\begin{array}{l}\text { Gerenciador de Dados, Aplicativos e } \\
\text { Interface com a Urna Eletrônica - } \\
\text { GEDAl-UE }\end{array}$ & $\begin{array}{l}\text { Software desktop criado com o objetivo de prover } \\
\text { as informações necessárias ao correto } \\
\text { funcionamento da Urna Eletrônica. }\end{array}$ \\
\hline $\begin{array}{l}\text { Sistema de Apuração de Votação } \\
\text { Paralela - SAVP }\end{array}$ & $\begin{array}{l}\text { Sistema de auditoria para auxiliar votações } \\
\text { monitoradas por fiscais dos partidos políticos. }\end{array}$ \\
\hline Sistemas internos da Urna Eletrônica & $\begin{array}{l}\text { Aplicativos de votação, apuração, justificativa } \\
\text { eleitoral, carga de UE, assinatura e validação, } \\
\text { gerenciador de aplicativos, iniciador da UE, } \\
\text { recuperador de dados, visualizador, validador de } \\
\text { fotos, verificação pré e pós eleição, autoteste da } \\
\text { UE, testador exaustivo, sistema de certificação e } \\
\text { autenticador de UE. }\end{array}$ \\
\hline Linux para Urna Eletrônica - UENUX & $\begin{array}{l}\text { Software com objetivo de unificar os sistemas } \\
\text { operacionais da UE, evitar pagar por licenças } \\
\text { adicionais para cada urna fabricada e também } \\
\text { para criar uma aplicação estável. }\end{array}$ \\
\hline
\end{tabular}




\subsection{Vinculação dos dados às proposições}

Para este estudo de caso foi considerado a abordagem de proposições teóricas e a análise de evidência em termos dessas proposições [Schramm 1971, Yin 2005].

Na primeira proposição teórica pressupôs-se que o processo de trabalho do Scrum é uma ação cognitiva produtora de conhecimento permitiu formular uma questão fundamental para a pesquisa, qual seja investigar uma pedagogia para este processo que responda ao requisito da participação e seja, ao mesmo tempo, construtivista dos conceitos necessários para a capacitação das pessoas à implementação de um desenvolvimento sustentável, bem como das soluções tecnológicas criadas atenderem ao interesse público de eleições justas, onde, a população exerça o seu direito constitucional de escolha dos seus representantes.

Na segunda proposição pode-se confirmar que a implantação das metodologias ágeis se adequou ao processo de planejamento do TSE, uma vez que, os objetivos de negócio foram alcançados com sucesso desde a sua implantação e entrega do UENUX, primeiro produto desenvolvido pelo TSE nos moldes ágeis, agregando conhecimento a racionalidade da cultura organizacional.

$\mathrm{Na}$ terceira proposição observou-se que é indispensável à promoção do desenvolvimento de software ágil de forma sustentável vinculada à capacitação das pessoas envolvidas nos projetos de produção dos softwares eleitorais proporcionando a melhoria contínua da qualidade dos produtos entregues. Ficou evidenciado que o TSE investe na capacitação interna e, além disso, faz parceria com instituições especializadas na área de segurança da informação, por exemplo, para auxiliar na lisura do processo eleitoral.

\subsection{Critérios para interpretação das descobertas}

Foram considerados os seguintes critérios para a interpretação das descobertas:

- Validade Interna: foi estabelecido o relacionamento causal explicando que em determinadas condições (causas) levaram a outras situações (consequências). Testou-se a coerência interna entre as proposições iniciais, desenvolvimento e resultados encontrados.

- Validade Externa: foi estabelecido o domínio sobre o qual as descobertas poderiam ser generalizadas. Testou-se a coerência entre os achados do estudo e resultados de outras investigações assemelhadas em órgãos da administração pública federal.

- Confiabilidade: o estudo utilizou informações públicas em observância a lei federal $n^{\circ}$ 12.527/2011: "Art. 50 - É dever do Estado garantir o direito de acesso à informação, que será franqueada, mediante procedimentos objetivos e ágeis, de forma transparente, clara e em linguagem de fácil compreensão."

\subsection{Execução da coleta de evidências}

O uso de múltiplas fontes de evidência permitiu o desenvolvimento da investigação em várias perspectivas - investigar vários aspectos em relação ao mesmo fenômeno. As 
conclusões e descobertas ficaram mais convincentes e apuradas já que foram advindas de um conjunto de corroborações.

A formação de uma cadeia de evidências consistiu em configurar o estudo de caso de tal modo que se consiga perceber a apresentação das evidências que legitimam o estudo desde as questões de pesquisa até as conclusões finais, por exemplo, assim como num processo judicial. A execução foi realizada da seguinte forma:

- Foram extraídos dados de documentos de domínio público disponíveis na página web oficial do TSE que auxilia o planejamento das iterações e controle/acompanhamento das tarefas realizadas pelas equipes de desenvolvimento;

- A partir das reuniões diárias do Scrum tornou-se possível compartilhar informações técnicas e do negócio, acompanhar a aplicabilidade da metodologia ágil de dentro da própria seção, e observar o comportamento individual das pessoas envolvidas;

- Entrevistas individuais com servidores e colaboradores que participaram da implantação dos métodos ágeis na seção proporcionou coletar diferentes perspectivas.

\subsection{Análise das evidências}

De acordo com [Yin 2005], "a análise das evidências é o menos desenvolvido e mais difícil aspecto da condução de um Estudo de Caso. O sucesso depende muito da experiência, perseverança e do raciocínio crítico do investigador para construir descrições, interpretações que possibilitem a extração cuidadosa das conclusões", sendo o mais importante nesta fase a definição de uma estratégia analítica geral, já que isso significa tratar imparcialmente as evidências, extrair conclusões analíticas e apresentar interpretações e descrições alternativas.

Dessa forma, a análise foi realizada por meio de cruzamentos das informações coletadas em documentos, software de gerência de projeto, entrevistas e observação. Com o objetivo de fazer um comparativo entre as atividades planejadas para as eleições 2012 e eleições 2014 visando perceber a evolução do nível de maturidade dos métodos ágeis utilizados pela SEVIN.

\section{Resultado do Estudo de Caso}

Nesta seção são apresentados os principais resultados e contribuições obtidas. De uma forma geral, esses resultados podem ser transformados em conhecimento e absorvido pelo negócio caso exista interesse da Administração Pública, no intuito de ganho de alguma melhoria ou vantagem competitiva em seus processos.

O objetivo foi analisar os aspectos positivos de uma implantação da metodologia ágil Scrum para gerenciamento dos projetos de desenvolvimento de softwares no TSE com o foco na construção do UENUX. Sendo assim, os artefatos gerados e o processo de trabalho foram comparados com os estabelecidos pelo Scrum e considerados aderentes com o framework. 
O processo de desenvolvimento concreto seguido pela equipe foi o seguinte:

- Definição da visão do produto - UENUX;

- Elaboração e atualização constante do Product Backlog, utilizando a prática Backlog Grooming para organização e refinamento das UserStories mais prioritárias, e assim, respondendo de forma rápida as mudanças de requisitos solicitadas pelo Product Owner - PO;

- Planejamento da iteração, sendo que, entram na Sprint apenas as UserStories que agreguem mais valor ao negócio e que são consideradas prontas pela equipe (DoR - Definition of Ready);

- As iterações possuem duração de duas ou três semanas, mas já foi observado pela equipe que sprints mais curtas se adaptam melhor ao time trazendo estimativas mais confiáveis das entregas;

- As reuniões diárias são realizadas com a moderação do ScrumMaster que visa manter a conformidade do processo, dando a palavra a todos e auxiliando o time na busca de soluções para os impedimentos;

- No final de cada iteração acontece a reunião de revisão da sprint, onde as funcionalidades consideradas feitas (DoD - Definition of Done) são apresentadas ao PO;

- Por fim, o time realiza a reunião de retrospectiva da sprint para avaliar quais técnicas e procedimentos de trabalho precisam ser melhorados ou incluídos na rotina da equipe;

A implantação das metodologias ágeis na SEVIN exigiu uma mudança cultural de toda equipe quanto à forma e rotina de trabalho, foram encontradas dificuldades, principalmente, falta de apoio das instâncias superiores e interação com as demais seções do TSE que continuaram utilizando as metodologias tradicionais.

Os principais benefícios que trouxeram os métodos ágeis comparativamente com os métodos anteriormente utilizados foram:

- Resposta ágil as mudanças nos requisitos durante o ciclo de vida do projeto;

- Antecipação de entregas das principais funcionalidades do sistema, proporcionando ao cliente uma visão realista da evolução do sistema a cada iteração;

- Maior colaboração do cliente no processo de desenvolvimento, possibilitando ao time sanar, rapidamente, dúvidas e impasses sobre as regras de negócio;

- Os erros nas estimativas de esforço planejadas diminuíram, uma vez que, com iterações e tarefas menores o time conseguiu definir melhor o tempo dedicado as atividades de desenvolvimento de software.

O desenvolvimento do UENUX, construído internamente no TSE, foi o primeiro software totalmente gerenciado por métodos ágeis, além disso, tinha características de ser um projeto complexo e problemático, uma vez que, foram substituídos sistemas operacionais proprietários adquiridos por meio de licitação pública - produtos de 
software de custo elevado de aquisição e manutenção - e que já estavam em produção em todas as urnas eletrônicas por todo o Brasil. Para trabalhar neste projeto foi formada uma equipe heterogênea, composta de colaboradores e servidores mais experientes em diversas áreas combinada com pessoas recém-chegadas que proporcionaram motivação e animação para o trabalho. Os bons resultados fizeram o projeto crescer e ganhar credibilidade perante a organização.

Para êxito na adoção do framework Scrum no projeto de construção do UENUX foi necessário disponibilizar aos membros da equipe uma maior autonomia e responsabilidade sobre suas ações, resultando em maior agilidade na execução dessas atividades, de acordo com os depoimentos dos envolvidos os profissionais estavam comprometidos com a metodologia adotada acreditando no aumento da produtividade proporcionado. Houve maior integração do Product Owner com a equipe de desenvolvimento e prévia padronização dos procedimentos.

Proposta técnica com sugestões de melhoria a partir dos resultados obtidos:

\subsection{Sugestões de Melhoria}

A primeira descoberta foi registrada ainda na fase de preparação para a coleta de evidências, durante a observação da rotina da equipe em suas reuniões diárias foi verificado que em determinadas situações de implementações de novas funcionalidades por programadores recentemente contratados seria recomendada a aplicação da técnica de revisão de código por desenvolvedores mais experientes. É fundamental que o conhecimento sobre as regras de negócio da Justiça Eleitoral e sobre a arquitetura dos projetos de softwares da SEVIN seja disseminado a atualizado periodicamente entre os times e as gerências.

A segunda constatação relevante foi que há necessidade de aprimoração da utilização da técnica TDD [Pressman 2011] para que os testes unitários considerem eleições em diferentes abrangências e cenários de testes mais diversificados e da implantação da técnica de programação em pares para o desenvolvimento de funcionalidades complexas.

$\mathrm{Na}$ fase de análise das evidências, durante a utilização do gráfico Burndown para monitoramento do progresso da iteração foi percebido que é necessário que os times prestem mais atenção na atualização das reestimativas a fim de tornar esta ferramenta mais útil e condizente com a realidade. Além disso, existe a necessidade de formalizar uma proposta relativa a adoção da prática de preparação para o planejamento.

Por fim, sobre a cerimônia de apresentação de resultados da iteração é recomendado que o foco seja no software em execução e feedback com relação aos resultados. Sendo importante a moderação pelo Scrum Master durante a apresentação a fim de manter o foco e a duração solicitada pelo Product Owner. Foi sugerido que a equipe avalie a possibilidade de reduzir a apresentação para no máximo 1 (uma) hora.

\subsection{Questões-chave do sucesso}

De acordo com a equipe envolvida na implantação do framework Scrum e com as pessoas que acompanham e utilizam os produtos entregues pela SEVIN à questão-chave do sucesso sempre foi o comprometimento e a paixão pelo trabalho no fortalecimento da 
democracia brasileira através da Justiça Eleitoral. Foram seguidos os seguintes passos para alcançar o objetivo de implantação bem sucedida:

- Alinhamento dos conceitos do framework entre os membros das equipes de desenvolvimento de software, por meio de workshops, dinâmicas e compartilhamento de bases de conhecimento e posts na internet;

- Ciclo de comunicação diário garantiu alinhamento de expectativas;

- Revisão de escopo constante proporcionou coesão no projeto;

- Entregas intermediárias do software buscaram o atendimento da necessidade do cliente e correção de falhas antes do final do projeto;

- Utilização do conceito de timebox em conjunto com o prazo determinado da realização das eleições forçou a equipe a ter o que entregar, evitando o prolongamento de atrasos.

\section{Conclusões}

Uma importante contribuição foi o aprendizado de novas metodologias e processos de software, as quais facilitaram e aceleraram o desenvolvimento da aplicação, como, por exemplo, a utilização do Extreme Programming combinado com o Scrum. O uso de um novo framework trouxe benefícios, mas ao mesmo tempo dificuldades, pois o desenvolvimento do projeto ocorreu paralelamente ao aprendizado deste framework.

A disponibilidade dos servidores e colaborados do TSE, foram importantes para auxiliar nas dúvidas durante o desenvolvimento do projeto, contextualizando em detalhes o histórico da implantação dos métodos ágeis na SEVIN no projeto de construção do UENUX, sendo um grande desafio para toda a equipe, possibilitando melhorar a análise das evidências e facilitar o entendimento sobre o assunto.

O proposto deste trabalho foi analisar os aspectos positivos de uma implantação da metodologia ágil Scrum para gerenciamento dos projetos de desenvolvimento de softwares no TSE. O objetivo do trabalho foi alcançado, e enumerado no relatório do estudo de caso, apresentado na seção 4. 


\section{Referências}

Bauer, P. (1969) "Software Engineering": A Report on a Conference Sponsored by the NATO Science Committee, NATO.

Swebok 3.0. (2014) "Guide to the software engineering body of knowlegment". Disponível em http://www.swebok.org. Acesso em 03/02/2014.

Pressman, Roger S. (2011) “Engenharia de Software”. 7. ed. São Paulo: McGraw-Hill.

PMI. (2012) "Um guia do conhecimento em gerenciamento de projetos". Guia PMBOK® 5a ed. - EUA: Project Management Institute.

Kniberg, H. (2007) "Scrum e XP direto das Trincheiras". 1a ed. São Paulo: C4Media Inc.

Schramm, W. (1971) "Notes on case studies of instructional media projects". Working paper, the Academy for Educational Development, Washington, DC.

Yin, Roberto K. (2005) "Estudo de caso: planejamento e Métodos”, 3a ed. São Paulo: Bookman.

Vazquez, C. (2013) "Análise de Pontos de Função: Medição, Estimativas e Gerenciamento de Projetos de Software”. 13ª ed. São Paulo: Editora Érica.

Schwaber, K. (2004) "Agile Project Management with Scrum". 1a ed. New York: Microsoft Press.

Varaschim, J. D. (2009) "Implantando o SCRUM em um Ambiente de Desenvolvimento de Produtos para Internet", Monografia ISSN: 0103-9741 PUC-RJ.

Cohn, M.; FORD, D. (2003) "Introducing an Agile Process to an Organization". Computer, v.36,p. 74.

TSE. Página oficial do tribunal: história das eleições no brasil. (2013). Disponível em: http://www.tse.jus.br/institucional/a-justica-eleitoral/historia-das-eleicoes-no-brasil. Acesso em 20/07/2013.

IEEE Standards Collection: Software Engineering, IEEE Standard 610.1241990, IEEE, 1993.

Múcio J. M. (2013) Acórdão no 2314/2013 do TCU, Utilização de métodos ágeis na Administração Pública Federal, TCU. 